\title{
Memorial and Western are leaders in incorporating technology in med schools
}

Published at www.cmaj.ca on Mar. 17

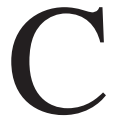
anadian medical schools are increasingly incorporating technology into their curriculum, though some are much further ahead than others.

"Everyone is on the train, but some are closer to the front," says Dr. Nick Busing, president and chief executive officer of the Association of Faculties of Medicine of Canada.

Two universities, for instance, have become leaders in incorporating electronic medical records into their undergraduate medical curriculum: Memorial University of Newfoundland in St. John's and the University of Western Ontario in London. To encourage other medical schools to catch-up, the Canadian Medical Association (CMA) and its subsidiary, MD Physician Services Inc., are offering the CMA's electronic medical record to all faculties of medicine in the country, along with free training for faculty and staff.

Though medical schools are embracing technology, some medical educators are concerned that the rate of adoption of new technologies isn't as fast or extensive as it should be. In its Jan. 28 report The Future of Medical Education in Canada (FMEC): A Collective Vision for $M D$ Education, the Association of Faculties of Medicine of Canada stated: "Based on rapid and evolving technological changes related to the way people communicate and learn, there must be increased understanding and use of tech- nology on the part of both faculty and learners at all MD education sites."

"This was one of the explicit enabling recommendations made in the project," says Busing.

There are certainly no objections savvy and eager to learn new technologies, he says, whether it be a medical records system or a surgical simulator or an imaging system. If anything, says Spadafora, young people entering medicine today are often better at learning new technologies than their teachers.

"In terms of their ability to just pick up technology and run with it, they have the advantage," says Spadafora.

A 2006 survey of medical students and residents about their perceptions of technology in medicine suggests that young people entering medicine are indeed excited about learning new technologies (Acad Psychiatry 2006;30: 470-9). Of the 160 respondents to the survey, $96 \%$ said that technology skills are important in medical training, $81 \%$ said teaching about technology skills should be part of their curriculum and only $5 \%$ expressed a discomfort with technology. "Trainees in medical education are technologically savvy and provide invaluable feedback regarding initiation, development and refinement of technological systems in medical training," the authors of the survey conclude.

Medical students and resiA 2006 survey of medical students and residents about their perceptions of technology in medicine found $96 \%$ believed that technology skills are important in medical training and $81 \%$ believed teaching about technology skills should be part of their curriculum. Only $5 \%$ expressed a discomfort with technology.

dents are not only good at picking up new technologies, they appear to enjoy it. They have grown up with technology and there is no intimidation factor. Dr. Leanne Tran, a

from medical students about incorporating more technology into their education, says Dr. Sal Spadafora, vicedean of postgraduate medical education at the University of Toronto in Ontario. Today's medical students are techradiology resident at the University of Western Ontario, says most residents receive their initial training on electronic medical records during their residencies and that those experiences are overwhelmingly positive. 
"Most of us who have been exposed to it have really liked it," she says. "It makes a practice more efficient."

Though training on the use of electronic medical records has not been added to most medical school programs yet, students are getting exposure to other forms of technology. The Internet, for example, is playing a growing role in medical education.

"When I graduated from medical school [in 2005], we were already shifting to web-based curriculum," says Tran.

Dr. Roona Sinha, who is completing her residency in pediatric hematology and oncology at BC Children's Hospital in Vancouver, British Columbia, also says that technology is becoming an integral part of medical education.

"I think we are entering a bit of a new era," says Sinha. "A lot of what we are doing now is simulation-based."

Being a doctor in the Information Age does pose its challenges, however. Parsing good information from bad is becoming more difficult due to the sheer amount of information available. And the fact that patients also have easy access to medical information and misinformation - can also cause problems.

"Patients are increasingly doing their own Internet searches, and a lot of what they find is good science but a lot is not good science," says Sinha. "One of the things we have to get better at is figuring out what on the Internet is valid and what is not valid. It takes a lot of extra time, and a lot more time to dispel some of the myths." - Roger Collier, CMAJ

DOI:10.1503/cmaj.109-3212 